\title{
Times Fluid, Mobile and Ambivalent: Constructing Racial \& Personal Identity in James McBride's The Color of Water
}

\author{
Yuan-Chin Chang (Corresponding author) \\ Department of Applied English Studies, China University of Technology \\ No. 56, Sec. 3, Xinglong Rd., Wunshan District, Taipei City 116, Taiwan \\ E-mail: yuanchin@cute.edu.tw
}

Received: 10-01- 2015

Accepted: 21-03- 2015

Published: 01-09- 2015 doi:10.7575/aiac.ijalel.v.4n.5p.63
Advance Access Published: April 2015

URL: http://dx.doi.org/10.7575/aiac.ijalel.v.4n.5p.63

\begin{abstract}
James McBride's memoir The Color of Water provides a rich and nuanced history of the author - a Black American man - and his white mother. Using the theories of Bhabha regarding hybridity, ambivalence and a Third Space between different cultures or individuals, it is demonstrated that racial and personal identities are constructed, and historically reconstructed, as flexible and mobile entities in this memoir. The linking of narratives and voices across different decades demonstrates the Third Space in the relationship between McBride and his mother, and each individual's relationship to and understanding of themselves in a broader multiracial culture. Lacan's theories regarding rhetoric and signification are also used to underpin an exploration of the ways in which McBride portrays his own changing understanding of biracial identity in America.
\end{abstract}

Keywords: identity, The Color of Water, multiraciality, Third Space, biraciality

\section{Introduction}

The Color of Water will be discussed and analyzed using the work of theorists including Jacques Lacan and Homi. K. Bhabha as grounding for assessing the issues surrounding identity and race in this novel-memoir. Commonly used as an educational text regarding multiracial identity in America (Soto, 1999; Winans, 2005), The Color of Water provides a nuanced and flexible viewpoint on race, change, movement and growth via the memoirist James McBride and his portrayal of his white mother's history. The Color of Water represents part of what has been termed a 'boom in biracial biography' (Spickard, 2001, p.76), and represents an understanding of a post-binary, post-hierarchical racial reality in modern America (Ramsey, 2005).

The title of the novel reflects several key elements in its portrayal of personal identity, racial identity and performance of duality in terms of race. The reference to the "color" of water is inherently ambivalent and impossible to quantify, as can be understood of McBride's - and others' - racial identity as it develops over his lifetime in parallel with his mother's earlier history. Like water, the theme of mobility, of movement and of change in states and perspectives underpins the identity formations in The Color of Water. Like water itself, characters' conceptualizations regarding racial identity in multiple locations and communities are fluid and difficult or impossible to contain within fixed and firm boundaries. Through this emblem of watery qualities, and the characters' own ambivalence about their perceived racial identities, McBride undermines the traditional, colonial-era hierarchical structuring of racial classification; a strict, simplified understanding of race as, literally, a black-and-white issue does not serve or portray the nuanced, ambivalent, hybrid and often-changing personal and cultural identities that individuals with biracial or multiracial families go through over the course of their lives.

It is important to discuss the sociological truths or verities that manifested themselves during the lifetimes of McBride and his mother. To commence, the miscegenation which gave birth to McBride clearly was viewed distastefully by the America of the first seven-tenths of the twentieth century. As noted in the text, the scions and daughters of mixed couplings often were the targets of verbal abuse and even physical violence. They were attacked for the color of their skin, and often - since being black was a nullity, or worse, to whites - they were compelled to retreat into the black community (McBride 2006). McBride saw a world in which there were clear reifications amongst the races: blacks did not step outside their strata or "mix" with whites. Consequently, they were forced into a world in which they either remained trapped in an uneasy, constrained space - or embraced a liminal space that could lead to their own demise.

The sociological conflict, and the accompanying pain that came to McBride as a result of his suffering life as a "mixed" American, is borne out in the text in various ways. He recounts the painful time when he retreated or distanced himself from his college sweetheart - herself the child of a mixed marriage - because he did not want his children to be like him (McBride, 2006). McBride was born in the late 1950s, so he would have been in his 20s during this time when he made the fracturing break from his beloved; suffice it to say, that means the distancing process (the sad event whereby he separated from this young woman) occurred in the late 1970s or early 1980s. America was changing at that time but, tragically, the reality for men such as McBride is that there was still perceived to be something "wrong" with mixed 
offspring. As a result, he fled from a possible relationship (even matrimony) with a woman he appeared to love.

As the world changes, McBride slowly changes and matures, too. He describes the ache of his childhood when he looked into the mirror and felt uncertainty insofar as he occupied a curious liminal space. As he grew - and as America grew - this uncertainty slowly went away (McBride, 2006). We see his own psychic truth in such passages: there are bumps along the way - the fear of commitment, the running away from a relationship because of an inbred self-loathing (or fear of the self) - but, at a slow and painful pace, McBride comes to accept himself and what he is. He ceases to be afraid of the color of his skin because he learns that the larger world has ceased to be afraid of it, too. If it may be said, the most poignant passage of the book, for this reader, is when he flees from love because he cannot bear for his children to be like - to look like - him. Stuck in a liminal space, his mature and inclusive self-view still nascent, he betrays himself almost as destructively as the bigots would have betrayed and assaulted him had the chance presented itself.

McBride demonstrates and articulates his own changing racial identity; he moves from a focus only upon his AfricanAmerican heritage and a sense of racial separation from his white mother, to a nuanced understanding and pride in his biracial identity. As the narrative of the memoir parallels the life experiences of his mother from the 1920s through the 1950s, mirrored with McBride's development from the 1960s through the 1990s, the changes in McBride's racial identity are clear. It can be seen that both McBride and his mother Ruth go through significant periods of eschewing self-determined White identity; as they mature, however, both develop a more relaxed and inclusive sense of their respective individual identities and experiences within the Black community. Notably, McBride's fusing of journalistic and memoirist techniques, and the temporal splicing of his own life story with that of his mother, means that the discussion and exploration of racial and personal identity in The Color of Water can take an exceptionally broad view of the historical roots of McBride's family history and the broader social history and currents flowing through twentiethcentury America. Performance, mobility, fluid and constant change, and a nuanced ambivalence all inform the modes of identity and identity-building evidenced throughout the memoir. Reference to Lacan's and Bhabha's theories regarding race, rhetoric and discourse will underpin this reading of The Color of Water.

\section{Passing and Performance: the Lacanian Lens}

Jacques Lacan, a French psychoanalyst, has had a significant influence in the area of literary criticism. Broadly speaking, Lacan's theories developed via his own readings and interpretation of the theories of Sigmund Freud; Lacan's theoretical work also includes elements of structural linguistics, and surrealism (Bowie, 1993). In a parallel with the theories of Freud, Lacan was firmly committed to the development of a rhetorical underpinning in literature; Freud was equally committed to such a rhetorical underpinning in the field of psychoanalysis. Lacan posited that all human knowledge - including the field of literature - had at least some discursive elements; this can clearly be extrapolated to a reading of The Color of Water that interprets racial and identity-based issues as represented in somewhat discursive fashion by McBride. Furthermore, Lacan describes the human experience as being essentially split between conscious and unconscious sides; the individual has access to their own conscious mind, while their unconscious emotions and desires remain at least partially inaccessible to them (Bowie, 1993). In the context of The Color of Water, it can be seen that individual performativity relative to race and personal identity can be understood in terms of this split between the unconscious and conscious elements of the human mind and the human experience.

Additionally, Lacan draws on linguistic concepts in order to connect his theory of the unconscious and conscious minds with rhetorical and performative practice in literature. This element of Lacan's linguistic theory holds that a particular sound or image can be directly connected to a rhetorical, linguistic, psychological or literary concept. The words comprising a piece of literature are themselves referred to by Lacan as signifiers (Bowie, 1993). Signifiers can, according to Lacan, produce meaning via the printed word; such meaning is constructed through their connection to such a concept. Furthermore, the relationships between multiple signifiers can affect their meaning. In the context of The Color of Water, the title and subtitle of the book itself and the consideration of race that permeates McBride's memoir.

The narrative and rhetoric of "passing" also relates to "the color of water" as a signifier under Lacan's theory. In terms of racial identity, "passing" refers to the ability of an individual to "pass" as a member of a different racial, gender or other identity group than the one to which they themselves primarily or partly belong (Nishime, 2005). For biracial individuals, some find that they are able to variously "pass" as a member of either race - for example, light-skinned individuals of mixed white and Asian heritage may be able to pass as white or as Asian, depending on the context and their identity performance (Berzon, 1978). An individual who is "the color of water" in terms of their identity and their performance can therefore be understood to pass between different identities and different groups. In the context of McBride's memoir, such "passing" is likely to occur in one direction only for McBride himself, and for his mother. For example, although McBride's mother had converted to Christianity, she retained the ability to "pass" in the Jewish community in which she had family roots. McBride himself was able to "pass" in the Black community, but not able to pass as white among strangers. The white-supremacist rhetoric of racial "passing" meant that McBride's mixed racial heritage was - on account of physical characteristics such as skin tone and hair texture - most likely to be interpreted by strangers as Black rather than White: 'If race is biological, a matter of hair and skin, then what happens when one's physical characteristics most closely resemble those of the members of another race? Of course, if race is some unalterable essence, then how is passing possible at all? What then is that essence?' (Nishime, 2005, p.39)

The issue of "passing" is itself fraught with problems, because there may well be disconnect or difference between an individual's racial self-identification - or lack of any specific and fixed racial identity - and the race to which a majority 
of strangers would assume that individual identifies. For example, a fair-skinned biracial or multiracial person may well be able to "pass" as having a white racial identity, and therefore may enjoy white privilege. According to Telles (2004), 'the light-skinned descendants in the United States ... have come to dominate their darker-skinned compatriots through discriminatory practices that derive from a racial ideology, creating what sociologists call racially stratified societies' (Telles, 2004, p.1). The very concept of passing is grounded on reinforcement of the "one-drop" approach to racial classification (Berzon, 1978). The one-drop approach reinforces a binary conceptualization of racial identity that is unlikely to serve multiracial or biracial individuals such as McBride himself.

In fact, in racial terms his mother's whiteness created difficulties for McBride as a young boy, when his older siblings and the greater Black community were drawn to Black Power concepts during the 1960s. In The Color of Water, Black Power is symbolized in the racecar that teenage McBride saw older boys riding. Everyone in the Red Hook neighborhood where McBride was raised was attracted to Black Power (the racecar), entranced by its speed and its sleek design. The racecar is a clear signifier of the real Black Power, and McBride's own ambivalence and fears about "passing" - physically or behaviorally -- in the Black community when his own mother was white. Sowell (1994) notes that 'race as a social concept is a powerful force uniting and dividing people' (Sowell, 1994, p.6); in the context of McBride's biography it can be seen that race unites him with his siblings and the greater community in which they live, while simultaneously dividing or distancing him from his own mother. Throughout The Color of Water, young McBride's fears for his mother in the context of Black Power as a movement; his white mother is a cultural and racial liability to young McBride, and he wishes that she could be transparent and colorless like water, rather than opaquely and problematically white: 'I thought it would be easier if we were just one color, black or white. I didn't want to be white. My siblings had already instilled the notion of black pride in me. I would have preferred that Mommy were black. Now, as a grown man, I feel privileged to have come from two worlds' (McBride, 2006, p.103). Once again, he grows and learns as time progresses.

Clearly, to McBride the issue of his biracial identity is problematic as a youngster. Notably, his attitude changed distinctly as he transitioned from adolescence to actualization as a grown man. As a biracial teenager in the context of Black Power and the 1960s, McBride felt resentful of his mother's race; however, his understanding of racial identity and his own biracial identity became more nuanced as he aged - in Lacan's terms, the "color of water" became more applicable as a signifier with a more flexible rhetoric and meaning that was not associated with a binary definition of race, and a status of conflict between Black and white racial groups, identities and social ideals. As a signifier "the color of water" can be taken to represent McBride's development of a more fluid and nuanced understanding of his own biracial identity - within his family, and within the wider world, he is able to navigate, flow and transition much like actual, literal water. The fluid characteristic of water becomes a rhetorical signifier regarding McBride's own fluid racial and personal identity.

\section{Multiraciality, Biraciality and Identity}

Considering the theoretical grounding of Homi K. Bhabha in relation to McBride's writing in The Color of Water, several of Bhabha's theories can be applied to the memoir. McBride's inherent ambivalence about his own biracial identity, and his white mother, can be understood in terms of Bhabha's post-colonial theory of ambivalence. Bhabha (1984) views culture itself as one of essentially oppositional dimensions and perceptions. This of course fosters a sense of duality or ambivalence when considering, as Bhabha customarily does, the experience and identity of the colonized in relation to the post-colonial society (Huddart, 2005). Bhabha (1984) argues that such ambivalence is inherent in the post-colonial condition, as each colonized individual carries a duality of identities - their own cultural, racial or ethnic identity, and the cultural identity of the colonizer. The imbalance of the power dynamic between colonizer and colonized peoples leads directly to this ambivalence on the part of the colonized person, who may feel resentment about the aspects of colonizer cultural identity that exist within their own identity and cultural experience. In the context of McBride's The Color of Water, such resentment and ambivalence can be seen in the aspects of racial and cultural identity experienced by McBride and his own mother. Of course, the context of The Color of Water is post-colonial, in that the United States is not a colonized nation. However, in terms of racial identity there is of course a parallel in that African slaves were initially brought to America by white settlers. Bhabha recognizes the traumatic nature of the colonial experience, and there is a clear parallel with the legacy of slavery in the modern United States. McBride's mother Ruth is shown to have ambivalence about her own racial identity and her whiteness: 'When I asked if she was white, she'd say, "I'm light-skinned," and change the subject' (McBride, 2006, p.xix). It can be seen that Ruth's former Jewish identity and heritage led to her exclusion from mainstream White culture and identity; further, she feels that selfidentification as white carries privilege and therefore guilt (Arminio, 2001).

Reviewing the subject matter, it is imperative that we refer to a medley of studies in order to highlight the differences between them - and how these differences can illuminate the underlying sociological pressures and fissures that defined (and continue to define) the America that McBride grew up in. For instance, there is the theory of hypogamy: this is a now antiquated and archaic theory which holds that blacks are only attractive to whites to the extent they possess some truly outstanding characteristic - great physical beauty, or uncommon educational attainment - that makes them appealing to "superior" whites. The black partners in mixed unions evidently (according to the basic contours of this theory) want to be associated with the perceived privilege and distinction of white society (Merton, 1941). This theory clearly stands in opposition to the racial ambivalence and even inchoateness that Bhabha (1984) describes in detail. What emerges from this is that, just as American theoretical paradigms gradually shifted away from rigid typologies towards something better, so too does McBride move away from an unhappy and uncertain self-identity (rooted in the 
sense that he is not what he is supposed to be) towards an inclusive, multiracial one.

Further, in McBride's biracial family it can be seen that there exists significant ambivalence regarding Americanization - Ruth appears to have quite comprehensively left behind her Orthodox Jewish family of origin, and they mourned her marriage to a Black American man. However, in the context of the United States, Ruth tells with ambivalence of the Americanization of her birth family and also her children; she indicates that her aunts - became increasingly materialistic with their time in the U.S.: 'Mameh's sisters were more about money than anything else, and any hurts that popped up along the way, they just swept them under the rug. They were all trying hard to be American, you know, not knowing what to keep and what to leave behind. But you know what happens when you do that. If you throw water on the floor it will always find a hole, believe me' (McBride, 2006, p.135). Ruth notes that her aunts' wealth-centric views on life are likely a result of their immigration and acclimatization to the materialist society in twentieth-century America. The process of acculturation as an immigrant can be seen as another way in which McBride articulates ambivalence as categorized by Bhabha. Ruth's quotation about water on the floor always finding a hole can be seen as an emblem of impermanence and transience in life; this is linked to an ambivalent immigrant experience in The Color of Water, and it relates to personal identity in the past, the present and the future. Inherently, McBride shows the tensions that arise in such ambivalence relative to the temporally-shifting personal identity in a cultural context.

Naming demonstrates the tension between the past and the present as an element of ethnic, religious and individual identity. McBride's mother has been through multiple complete changes of name, and to a degree each name change indicates a shift in her identity and experience. Ruth's original name was Ruchel Dwajra Zylska; this was Americanized to Rachel Deborah Shilsky when her family emigrated from Poland to the United States. Noting that her Jewish identity precluded her from being considered truly or fully "white", Ruth notes that she went to "the white school' rather than the Jewish school (McBride, 2006, p.80). Ridiculed for her religious background, Ruth changed her name further in an attempt at assimilation: 'the white kids hated Jews in my school.... I couldn't stand being ridiculed. I even changed my name to try to fit in more. My real name was Rachel, which in Yiddish is Ruckla, which is what my parents called me but I used the name Ruth around white folk, because it didn't sound so Jewish, though it never stopped the other kids from teasing me' (McBride, 2006, p.80). Upon her two marriages, Rachel changed her first and family names, as she was cast out by her family of origin for marrying a Black man in the segregated American South. Ruth's name changes represent the different stages of her life as a daughter, wife and mother; they represent her development over time while ambivalently attempting to reconcile the past with the present, her roots and her future. More broadly -- and relevant to considerations of personal identity, racial identity and a state of movement or of change - Kai (2014) indicates that the act of naming oneself or another person is highly ritualized, 'convey[ing] a power over things. It is an exercise of power because those who name also control' (Kai, 2014, p.1063). Ruth's name changes have varying degrees of self-control and external control; her original Polish name was modified by her father when the family moved to the United States; her subsequent name changes were related to Ruth's own new family as she married twice and had a total of 12 children. The names of the men Ruth married were Euro-centric and derived from white Europeans; yet in the context of multiracial and post-emancipation America, Ruth's taking of these names was a way to determine her own identity within multi-racial communities and within her own biracial family. According to Kai (2014), the act of naming oneself or another is particularly important among immigrants, women and minority populations - Ruth's life experience as a white immigrant woman living in communities of color has placed her in these demographic groups among which naming choices are significant and potent. Renaming oneself has been a way to reclaim power, and to determine one's own identity (Kai, 2014). Ruth's renaming has served to distance her from her Orthodox Jewish roots, from her Polishlanguage upbringing, and from her white family of origin. In escaping the control of her patriarchal and abusive father, Ruth has discarded her father's family name in a way similar to that in which African-American slaves commonly discarded the names of their former masters as a way of creating a new and independent identity (Kai, 2014, p.1063).

Ruth, and to an extent McBride, also represents Bhabha's concept of hybridity in identity. Bhabha indicates that multiculturalism - and by extension multi-raciality - leads to the development of novel cultural trends and norms. Bhabha (1984) uses his hybridization theory to depict colonialism as a dynamic force that affects the culture of a region or people long after the colonial period itself. Cross-cultural relationships and exchange are therefore constantly shifting and fluid in their development. McBride's own biracial identity can be understood as an iteration of such hybridity in personal identity; the temporal process of writing the memoir The Color of Water seems to be a process of hybridization in McBride's own character and his self-understanding:

I felt like a Tinkertoy kid building my own self out of one of those toy building sets; for as she laid her life before me, I reassembled the tableau of her words like a picture puzzle, and as I did, so my own life was rebuilt (McBride, 2006, p.270).

In terms of Bhabha's theories, this depiction of the writing process and change indicates a duality between McBride's preconceived notions regarding writing the memoir and his actual lived, fluid experience of writing the memoir. The book itself is a hybrid of personal memoir and journalistic, subjective research and reporting; McBride has a professional background in journalism and inherently brings this investigative, somewhat dispassionate approach to researching the history of his mother and his family. However, the subject matter is too deeply personalized for $\mathrm{McBride}$ to remain entirely in the mode of a journalist; in researching his mother's identity and life experience he is naturally drawn to reflect upon, and develop, his own personal identity and the ways in which his present experience is related to his mother's past. In this aspect, hybridity and ambivalence are tied together in the multiracial or post-colonial 
experience as discussed by Bhabha (1984); the connections between the past and the future, and the mysteriousness of the past, are relevant to both of these theories of identity and behavior. Ruth McBride Jordan is shown -- through her changes of name, identity and the time-span of her life as documented by her son - to be a woman in a constant state of adaptation, actualization and negotiation between past and present, Black and white racial identities, and hybrid cultural, religious and social identities.

Bhabha (1984) eschews the broad concept of cultural "diversity", basing his theory instead on a concept of cultural "difference". In Bhabha's view, this linguistic difference represents a distinction between the existing knowledge of a historical culture which then becomes diverse, and the potentially tense or problematic meeting of two or more cultures. In this aspect, cultural difference instead of cultural diversity is an appropriate lens through which to view biracial or multiracial society and individual identity or behavior - as demonstrated by McBride in his portrayal of his mother and his own development, the ambivalence and hybridity of their respective identities is a true, problematic hybridization rather than a simple "addition" of one racial identity to another historically-established identity and practice. Bhabha (1984) detects a cultural supremacy in the concept of cultural diversity instead of cultural difference; in this aspect it can be considered analogous to the supremacist ways in which race is codified and discussed in the modern United States. Understanding difference rather than diversity represents a way in which racial identity can be separated from simplistic and divisive signifiers such as skin tone and other physical characteristics. Colonial-era discourse (Bhabha, 1984) functions on a concept of fixed and delineated categories, races or cultures that can exist separately in a state of diversity within a particular geographical region; stereotyping itself is based in such conceptualization of the fixed nature of racial characteristics and factors. However, Bhabha's theory of cultural difference allows for a more fluid understanding of racial and cultural identities, and - like McBride's memoir in The Color of Water - affords the possibility of fluid, changing, hybrid or seemingly contradictory identities to exist within a single lifetime, a single person, or a single place in time. Bhabha (1984) and McBride alike capture the fluidity of cultural and racial identity in individuals and groups; this is an underpinning of Bhabha's hybridity theory and McBride's memoir narrative concerning his mother. The difficulties of McBride's growing up in the Black Power era with a white mother can be seen as a representation of the problematic nature of "fixed" thinking regarding culture and race; both Bhabha and McBride move towards a more nuanced and dynamic iteration of what racial identity and cultural identity mean over the course of consecutive decades. McBride's earlier assertion that 'I thought it would be easier if we were just one color, black or white' (McBride, 2006, p.103) represents this fixed, binary thinking about race; however, McBride develops a more nuanced and fluid understanding of his own biracial identity and that of his family and broader culture. The emblem of water, used throughout The Color of Water with multi-faceted meanings, also sums up this idea of hybridity or duality. Water is fluid and mobile, like the passage of time itself; water can move from one place to another without losing its own characteristics. Furthermore, the ability of water to absorb or dilute another substance or liquid means that it can be seen as a symbol of binding multiple substances together. In this aspect, water can be seen as a common binding agent in a culture of difference as envisioned by Bhabha (1984).

Connected to this idea of hybridity and fluidity is Bhabha's (1990) theory of the Third Space. The Third Space is based in ambiguity, and Bhabha (1990) locates this theoretical space at the intersection of two or more cultures or individual people. According to Bhabha, the Third Space provides an alternative to understanding historical and cultural identities as inherently and historically unified. The Third Space allows for a conceptualization or understanding of identity as not being rooted in a single past point of origin or a singular cultural tradition. An understanding of the Third Space is inherently ambiguous as a mode of discourse, as it acknowledges the undefinable boundaries and blurred edges of cultures or individuals in interaction with one another as time passes and their interrelationship changes. Bhabha's Third Space is a less hierarchical system than the traditional viewpoint of cultures or races as distinct from one another; of course, this idea of hierarchical cultural structure is one of the major problems Bhabha and others see with the colonial era and its legacy. Bhabha's Third Space allows for reappropriation of the past, and reinterpretation of the meaning of past and present developments. This is absolutely what McBride undertakes in his memoir of his mother, himself, and his biracial identity in the modern United States. In this alignment with Bhabha's theories of hybridity, ambivalence, temporality and the Third Space, McBride also finds theoretical commonality with the deconstructionist thinking of Derrida, Lacan's psychoanalysis as it relates to literary work, and the shared idea between Lacan and Foucault that literature is inherently discursive or rhetorical to at least some degree.

Before moving onwards, there is another theory - Blau's theory of social structure - which must be noted as an antidote to previous theories, such as Merton's theory of hypogamy. Chiefly, this theory notes that diminished residential segregation and diminished socio-economic differentiation leads to greater positive associations between and amongst blacks and whites. Furthermore, communities that feature greater instances (more frequent manifestations) of intermarriage tend to be relieved of the excessive interracial violence that defines other communities where such intermingling is less common (South \& Messner, 1986). This theory suggests more fluidity and mobility in socioeconomic relationships between blacks and whites than does Merton's theory of hypogamy. There is a sense that the liminal space can be crossed and that socio-economic barriers can be lowered or (in the most salutary instances) removed outright. Applying what has been discussed above, whites are not automatically superior (in an institutional, racial or economic sense) than blacks. Again, this insight segues into a larger discussion about hybridity and fluidity as described by Bhabha. People can "mix" (for want of a better term) and ambiguity can (while obviously posing challenges) become its own vigorous strength.

Racial and personal identity in The Color of Water is inexorably linked to the concept of multiraciality. As can be seen from a survey of recent literature, the very concept of multiraciality is somewhat fraught, disputed and subject to 
multiple interpretations according to time, place and individual perspective. Hernandez indicates that some individuals advocated for the inclusion of a multiracial category in the Census, arguing that forcing individuals to choose one of several mutually-exclusive racial categories was unfair and disrespectful: 'In the absence of a legal right to demand a multiracial category, the multiracial movement might consider not responding to the race question at all, in order to pressure the federal government to modify its classification method' (Hernandez, 1997, p.38). According to Rockquemore (1998), the subsequent introduction of a multi-racial category to the 2000 U.S. Census was controversial due to its assumption that "persons of mixed-race parentage identify as "biracial" or "mixed" and will continue to do so if given the opportunity on government documents' (Rockquemore, 1998, p.197). As demonstrated by McBride in The Color of Water, his identification was variously as Black then as biracial. McBride notes that his older siblings instilled in him a sense of Black pride; there was no correlating sense of "biracial pride". Furthermore, the historical practice of separating Black and White racial classifications as binary definitions - and the so-called "one-drop" rule, which holds that a person with one-drop of non-White blood is not white (Roth, 2005) - meant that McBride was not alone in identifying as Black before identifying as biracial. Telles (2004) indicates that "the vast majority of persons in the United States with any African origin are categorized as black' (Telles, 2004, p.1). Furthermore, the "biracial" category carries an element of inherent rhetoric, recalling Lacan's theory, insofar as it implies that each of the individual's parents belong to only one racial category or background. Rockquemore (1998) indicates that individuals with biracial or multiracial backgrounds have very little common ground in terms of interpreting their own racial identities. Racial identity for this group is a broad spectrum, and there are 'multiple ways individuals understand and respond to their biracialness' (Rockquemore, 1998, p.197). It is interesting that Rockquemore (1998) indicates social networks are important in determining how an individual with biracial or multi-racial heritage defines and experiences their own racial identity as a lived experience. In the context of McBride's memoir, it is made clear that in the context of his mother's early life in the United States, her biracial children are considered Black, not white.

In considering the challenges of navigating a biracial or multiracial identity in the modern U.S., it is worth examining the history of race-based ideologies and classifications. The United States has a multiracial society today largely because of the history of slavery, when Africans were brought to America by European colonizers (Kwan \& Speirs, 2004). Over the course of history since the era of slavery, racial identity, race-based power and the degree of racial democracy have all been constantly-changing and controversial aspects of life in North and South America alike (Bailey, 2009; Daniel, 2010; Skidmore, 1992). An ideology of assimilation has been used as a means of denying white privilege and denying the presence of any race-based problems in post-slavery societies. Assimilationism can be understood as grounded in what Bhabha calls "cultural diversity", a more rigid and hierarchical approach to understanding race than the "cultural difference" understanding that is more in line with McBride's portrayal and understanding of his own family background. Throughout McBride's book, societal-level problems relating to race are exposed and discussed. To give one example, Ruth's father ("Tateh") is portrayed as a racist and abusive man; having failed to secure work in America as a rabbi, Tateh opened a store in a predominantly Black area of Suffolk, VA.

\section{Race, Identity and History}

Daniel (2010, p.9) indicates that even the concept of race as a system of distinct categories is relatively modern. Until the early 1700s, when European powers began competing with one another in Africa, America and Asia, there was little to no use of race-based ideologies in justifying or structuring national expansionism, conquest and the global slave trade (Daniel,. 2010). It was only once 'Spain, Portugal, Italy, France, Germany, Holland, Denmark and England' (Daniel, 2010, p.9) began to compete in the same territories that race-based ideologies began to be utilized. A hierarchical definition of, and conceptualization of, race and racial categories was used by European powers seeking to justify 'both the conquest and a unique form of slavery' (Daniel, 2010, p.9). According to Daniel (2010; 2013), there was also a religious aspect to this hierarchical understanding of racial categories, groups and identities; namely, 'Christian Europe viewed itself as morally superior to the darker-skinned infidels of the Afro-Eurasian world' (Daniel, 2010, p.14). During the colonial era there was an indubitable prevalence of hierarchical structures according to religion, social elements and racial factors. In The Color of Water, it can be seen that religion is a unifying point between McBride and his mother, as both believe in a Christian God and find strength and shared experience in their religious faith. However, religion is another area in which McBride's mother Ruth has undergone a shift in identity, performance and practice over the course of her life - she was raised in the Orthodox Jewish tradition which she later abandoned. Although the modern United States theoretically practices the separation of church and state, there is still a stratified and hierarchical ideology relating to both race and religion in many areas. In the Virginia and the Red Hook, New York that McBride writes about in The Color of Water, it can be seen that the stratified system of racial classification established during the colonial and slavery eras, persisted - along with ideological Euro-centrism - and served to undermine the ideal of the modern United States as a racial democracy. A Euro-centric ideology informed the way race is conceptualized and considered in colonial and post-abolition America. Under the Euro-centric paradigm, Daniel (2010) indicates that 'blackness and whiteness represent the negative and positive designations, respectively, in a dichotomous hierarchy premised on the "law of the excluded middle" and grounded in African and European racial and cultural differences' (Daniel, 2010, p.27). However, in the modern United States, this "excluded middle" of individuals who fit into neither of the historically-understood binary racial categories represents a significant proportion of the overall population (Hernandez, 1997). At the time of writing, the United States is clearly a multiracial society (Dalmage, 2004; Zack, 2004). However, the racial segregation that took place in the United States was based on a Euro-centric and binary categorization of race in the categories of black or white (or alternatively, white/nonwhite). Furthermore, Butler's theories of performativity can be used to understand the characters in The Color of Water, and their respective journeys toward creation of distinct 
personal and racial identities in the modern United States. McBride can be seen, variably, to perform whiteness through various behaviors and actions. Just as Butler sees gender as a rehearsed performance rather than a selection of fixed biological categories (Butler 1997), race can also be viewed as a performance rather than an inflexible division based on genetics.

Hollinger (2003) gives perspective on the context in which McBride's mother came of age in the United States, and specifically in the Southern state of Virginia. The Color of Water focuses on Ruth's life from the 1920s through the 1950s; James McBride's life as retold in the book is presented in tandem with his mother's experiences from the 1960s through the 1990s. As late as 1958, according to Hollinger, the state of Virginia had a miscegenation statute that outlawed inter-racial marriage. Hollinger (2003) presents the case study of a young couple who had married in the District of Columbia but were then arrested on felony miscegenation charges at home in Virginia. The couple was 'found guilty of violating the statute's prohibition on marrying out of state with the intent of circumventing Virginia law' (Hollinger, 2003, p.1). This was the context of legal and enforced racial segregation in which Ruth found herself pregnant in an unmarried inter-racial relationship and terrified of the consequences for James's father. In The Color of Water, Ruth relays the strict racial segregation of Suffolk, Virginia at the time she lived there: 'Suffolk was a one-horse town back then, one big Main street, a couple of movie theaters - one for black folks, one for white folks - a few stores, a few farms nearby, and a set of railroad tracks that divided the black and white sections of town' (McBride, 2006, p.39). Later, when the family lives in Red Hook within New York City - and later in the narrative, during his teenage years, in Wilmington, DE -- McBride sees similar divisions and borders between communities of different descent or heritage; while the miscegenation laws are no longer applied, informal segregation and separation continue. The question of racial segregation or integration is particularly acute in the modern United States, as 'Americans have mixed in certain ways and not others, and they have talked about it in certain ways and not others' (Hollinger, 2003, p.2).

By looking to Ruth's past as early as the 1920 s, McBride uncovers common threads and developments that reach to his adult life in the latter part of the twentieth century. In keeping with Bhabha's theories of hybridity and a culture of difference rather than one of diversity, McBride continually returns to the theme of time's passing. This relates to the tension between the past and the present in the interwoven story of McBride's and Ruth's lives over the span of multiple decades. Both individuals are shown to be broadly respectful of their own early lives, and their pasts, while seeking reconciliation, hybridity and compromise in their current and adult identities and belief systems. Ruth has a need to reconcile her early experiences as a new immigrant of Orthodox Jewish faith, and her adult status as a Christian mother of 12 Black children. It appears that Ruth largely rejects her family of origin, who cast her out on account of her association with Black people. McBride's own negotiation and compromise with his past also involves an increasing hybridity of cultural and personal beliefs and identity; early in his life the civil-rights movement had led McBride to emphasize his Black heritage rather than considering himself biracial and influenced also by his white mother.

The American Northeast of the 1960s through 1990s is not shown by McBride to be a post-segregation haven of racial harmony. Throughout the time period examined by The Color of Water, it can be seen that characters and groups are routinely and thoroughly excluded from the dominant cultural, racial or religious group on account of their differences. Early in the narrative, Ruth is ostracized and openly ridiculed as a result of her Jewish faith in the context of the American South. Ruth's father, like others in the Northern communities where McBride grew up, engages in racist stereotyping and exclusion of Black people; McBride himself initially seeks to exclude himself from the biracial or white demographics by leaning towards and favoring his Black heritage and identity. Over the course of the memoir, both Ruth and McBride are seen to become more mature in their understanding of identity and exclusion; each grows towards an understanding of what Bhabha terms hybridity, ambivalence and the cultural Third Space between two or more identity groups. In such a Third Space, individual self-definition and a degree of personal freedom are possible Ruth's narrative serves as an example of such relative freedom flowing from her decisions and her understanding of her own identity. Ruth's work ethic is impressive, and this is passed to her children who all find maturity, professional identity and a degree of independence via education and their mother's work ethic. In some ways, the professional identities developed by McBride and his siblings represent forms of personal actualization that transcend or hybridize individual racial identity.

\section{Discussion and Conclusions}

The way in which McBride manipulates the temporal narrative in The Color of Water is effective in delineating such a hybridity or Third Space between his life experience and that of his mother; McBride's memoir and memories are interwoven with those of his mother. The net effect is that the reader can compare McBride's experiences at a certain life stage or age alongside those of his mother at a similar age or stage. Both are portrayed during young adulthood as a particularly crucial time for the development of self-directed, hybrid identity in Southern and Northern contexts. Ruth is shown to broadly reject her early roots - her family of origin, her original Orthodox Judaism, and the American South itself. Hobson (1999) discusses the concept of a racial "conversion" in terms of self-identity in the context of the historical American South. Ramsey (2005) indicates: 'the South is not so much a place as an amorphous cultural space where history yields to symbolic simulations that have no stable correspondence to reality' (Ramsey, 2005, p.119). Ambivalence and shifting realities - and individual negotiation with or escape from those realities - underpin McBride's portrayal of the American South via his mother's life history. Discussing the racial tension in 1920s and 1930s Virginia, Ruth said that under surface-level calm there was something like a bomb waiting to go off (McBride, 2006). Ruth loathed the racism and segregation of the South, and her disgust with the South meant she barely set foot in the region after moving North with her family. 
Family history, and the mysteriousness of Ruth's family background, recurs as narrative motifs throughout The Color of Water. Secrecy returns as an emblem throughout Ruth's life, and this has a clear effect upon her own family that includes McBride. It is the journalistic process of researching and writing the book that brings McBride to a greater understanding of his mother's mysterious early life, and her reasons for keeping secrets over the course of her lifetime. Sadly, one of the earliest secrets that Ruth had to keep was being seriously sexually abused by her father throughout childhood. This family secret, a reason for Ruth's general reluctance to speak about her family of origin with her own children, was uncovered during the memoir-writing process and goes some way towards explaining the fracturing of Ruth's birth family and the fact that several members of the family simply do not maintain relationships with one another as adults. These past secrets undoubtedly explain Ruth's self-sufficient and independent identity as an adult. Further, Ruth's first pregnancy, with her black boyfriend Peter in the segregated South, had to be kept secret because of the physical danger to them both should their relationship be known. Following complete alienation and separation from her family of origin, Ruth found some solidarity in the Northern Black communities where she lived with McBride's father.

The emblem and quality of water, as reflected in the memoir's title, embodies several key themes of the book as they relate to personal and racial identity and performance. Lacan's theory of rhetoric and signifiers, paired with Bhabha's ideas regarding hybridity, ambivalence and a cultural Third Space, can be seen in the motivic and emblematic references to water, color and identity. One of the major motives that relates to all these theories, and to water itself, is the theme of movement. McBride portrays his mother's various forms of movement throughout the narrative of the memoir as facets of her identity and behavior. Moving and changing are themes recurring throughout Ruth's life - in geographical terms she moves between Northern and Southern communities and regions of the United States. In physical terms, Ruth is portrayed as constantly in motion; this appears to be one of the ways in which she navigates and negotiates her reality. The emblem of Ruth's bicycle-riding through the Black neighborhood in which the family lives is a recurring motif in The Color of Water; although McBride is at first embarrassed by Ruth's cycling habit, he comes to understand it as part of her self-sufficient and self-powered approach to her life. Similarly, the act of physical movement represents a form of escape for Ruth, as it has since her early life: 'I'm claustrophobic. I can't stand feeling stuck or trapped in a place, I like to move. Even as a tiny girl I was like that. Hobbies? I had none. Running. That was my hobby. Sometimes when Tateh wasn't home, I'd tear out the door of the store and run. Just run anyplace... I was always a running-type person. Of course I had something to run from' (McBride, 2006, p.42). Whether running or cycling, Ruth's physical movement represents an escape from proximity to, first, her abusive father and difficult family of origin, and later the chaos of her home life. Movement through physical space, like flowing water, allows Ruth to negotiate emotional and mental space for herself throughout her life. Ruth's use of movement as a coping mechanism is transferred to her children, as she instills in them the importance of self-sufficiency and a constant work ethic. Ruth pushed all her children to remain in a constant state of activity and motion - this functioned to help them default to productive rather than destructive behaviors, simultaneously giving the children an external focus as distraction from overly dwelling on the problems of being biracial in twentieth-century America. For Ruth and the other family members portrayed in The Color of Water, physical movement and the emblem of the bicycle represent a form of identitynegotiation, mitigation of reality, and an emotional escapism via physical escape of closed or confined surroundings. The emblem of physical flight from a situation is also established in Ruth's mother's singing "Birdie, birdie, fly away". Ruth's need for constant physical motion is contrasted with her Mameh's physical disability and inability to escape Ruth's father or the South.

Following Bhabha's theory of ambivalence and hybridity, the concept of mobility is central to an identity-based understanding of The Color of Water. In terms of self-defined identity, both physical and mental mobility allow characters portrayed to re-make or re-define themselves; this is evident in the mobility of McBride's own biracial identification over the course of the memoir. He begins, like his siblings, acknowledging only his African-American heritage in the context of Black Power. However, his racial identity becomes more fluid, nuanced and malleable over time, as he acknowledges the fact that his white mother has been a huge influence on not only his genetic make-up, but also his behavioral and cultural identities in Bhabha's "Third Space". Other, non-physical forms of movement are evidenced throughout The Color of Water; Ruth's multiple re-namings represent a form of identity movement and a process of changing "path" in terms of the identity projected to oneself and to the outside world. McBride, alike, undergoes similar changes or movements in his mental and emotional realms relative to his racial and personal identity. Movement, change and fluidity allow the characters in The Color of Water to constantly redefine themselves and their identities in an ambivalent and hybrid context.

\section{References}

Arminio, J. (2001). Exploring the nature of race-related guilt. Journal of Multicultural Counseling and Development, 29(4), 239-252.

Bailey, S. (2009). Legacies of race: Identities, attitudes, and politics in Brazil. Stanford University Press.

Berzon, J. R. (1978). Neither white nor black. The mulatto character in American fiction. New York: New York University Press.

Bhabha, H. (1994). The location of culture. London: Routledge.

Rutherford, Jonathan. (1990). The third space: interview with Homi Bhabha. In Jonathan Rutherford (Ed.), Identity: 
Community, culture, difference, 207-221. London: Lawrence and Wishart.

Bowie, M. (1993). Lacan. Harvard University Press.

Butler, Judith. (1997). Excitable speech: A politics of the performative. London: Routledge.

Dalmage, H. M. (Ed.). (2004). The politics of multiracialism: Challenging racial thinking. SUNY Press.

Daniel, G. R. (2010). Race and multiraciality in Brazil and the United States: converging paths? Penn State University Press.

Hernandez, T. K. (1997). Interests and rights of the interracial family in a "multiracial" racial classification. Journal of Family Law, 36, 29.

Hobson, F. (1999). But now I see: The white southern racial conversion narrative. Louisiana State University Press.

Hollinger, D. A. (2003). Amalgamation and hypodescent: The question of ethnoracial mixture in the history of the United States. The American Historical Review, 108(5), 1363-1390.

Huddart, D. (2005). Homi K. Bhabha. London: Routledge.

Kai, I. H. (2015). From root to route: Identity, mobility and renaming in James McBride's the color of water. International Journal of Social Science and Humanity, 5(12), 1062-1067.

Kwan, S., \& Speirs, K. (Eds.). (2004). Mixing it up: Multiracial subjects. University of Texas Press.

McBride, J. (2006). The color of water (10th anniversary edition). Penguin.

Merton, R.K. (1942). Intermarriage and the social structure. Psychiatry, 4(3), 361-374.

Ramsey, W. M. (2005). Knowing their place: Three black writers and the postmodern south. The Southern Literary Journal, 37(2), 119-139.

Rockquemore, K. A. (1998). Between black and white: Exploring the "biracial" experience. Race and Society, 1(2), 197-212.

Roth, W. D. (2005). The end of the one-drop rule? Labeling of multiracial children in black intermarriages. Sociological Forum, 20(1), 35-67.

Skidmore, T.E. (1992). Fact and myth: Discovering a racial problem in Brazil. Kellogg Institute Working Paper, 173, 123.

Soto, L. D. (1999). The multicultural worlds of childhood in postmodern America. In Carol Seefeldt (Ed.), The Early Childhood Curriculum: Current Findings in Theory and Practice, 218. New York, NY: Teacher's College Press.

South, S.J. \& Messner, S.F. (1986). Structural determinants of intergroup association: interracial marriage and crime. American Journal of Sociology, 91(6), 1409-1430.

Sowell, T. (1994). Race and culture: A world view. New York, NY: Basic Books.

Spickard, P. (2001). The subject is mixed race: the boom in biracial biography. In David Parker \& Miri Song (Eds.), Rethinking 'mixed race', 76-98. London: Pluto Press.

Telles, E.E. (2004). Race in another America: the significance of skin color in Brazil. New Jersey: Princeton University Press.

Winans, A. E. (2005). Local pedagogies and race: Interrogating white safety in the rural college classroom. College English, 67(3), 253-273.

Zack, N. (2004). American mixed race: The United States 2000 census and related issues. In SanSan Kwan \& Kenneth Speirs (Eds.), Mixing it up: Multiracial subjects, 13-30. University of Texas Press. 